\title{
Perspective of Nuclear Medicine in Bangladesh starting in The New Decade of 2021
}

\author{
Nurun Nahar \\ Correspondence Address: Professor Dr. Nurun Nahar, Director, National Institute of Nuclear Medicine and Allied Sciences (NINMAS), \\ Block-D, BSMMU Campus, Bangladesh Atomic Energy Commission, Dhaka, Bangladesh. Email: nahar_ndr@yahoo.com
}

Bangladesh is going to celebrate its golden jubilee of independence in 2021. It is a matter of great pride that in this period Bangladesh has moved forward in almost all sectors. The country has made remarkable progress in reducing poverty, supported by sustained economic growth. The per capita income is increased from $\$ 543$ (2006) to \$1909 (2018). Bangladesh reached the lower middle-income country status in 2015. In 2018, Bangladesh fulfilled all three eligibility criteria for uplifting from Least Developed Countries (LDC) and is now well on track for graduation into a developing country in 2024 (1).

Health sector development of Bangladesh is also remarkable in last few decades and a topic of keen interest for others. Average life expectancy of 66.5 years (2006) has increased to 72.3 years (2018). Maternal mortality rate is reduced from 3.37 per thousand in 2006 to 1.69 per thousand in 2018 , side by side, infant mortality rate has reduced from 48 per thousand (2006) to 22 per thousand (2018) (2).

Bangladesh has a rich history of Nuclear Medicine (NM). The first NM center was established in 1962 in a tin-shed building of Dhaka Medical College. However, before independence of Bangladesh only three NM centers were there, the other two located in Chittagong and Rajshahi (3).

We have seen the main growth of NM in Bangladesh at the nineties. Bangladesh Atomic Energy Commission (BAEC) under the Ministry of Science and Technology (MOST) has played the most significant role in this development. With the advent of new radiopharmaceuticals and instrumentations, NM has reached a new height in medical diagnosis and treatment. Keeping with the pace, BAEC has also modernized all the NM centers with either construction of new buildings or renovation of the old ones and procurement of new instruments including planar and SPECT gamma cameras. A few SPECT-CTs and PET-CTs are installed in different institutes. First public PET-CT was established at National Institute of Nuclear Medicine and Allied Sciences (NINMAS), Dhaka and providing regular services to patients since January, 2016. Almost all the $15 \mathrm{NM}$ institutes under BAEC now have a fresh new look. The first cyclotron of the country in government sector is going to be commissioned soon at NINMAS. However, some big private hospitals and a few hospitals under the ministry of health also came forward. The combined military hospital $(\mathrm{CMH})$ in Dhaka also established a very functioning center with PET-CT facilities. At present some $20 \mathrm{NM}$ centers / institutes are offering full-fledged services in different parts of the country (4).

The number of people who can affordably access diagnostic medical care in Bangladesh has increased three times over the last ten years, as the country has expanded and strengthened its NM services. With overwhelming support of the IAEA and MOST, a steady service was possible by BAEC to build a well managed NM system comprising of well-trained medical staff, advanced imaging tools and a cost-effective source of essential radiopharmaceuticals (5).

Bangladesh will be a middle-income country in the next decade starting in 2021 and more people will avail the sophisticated and better medical services. Keeping that in mind, BAEC is implementing several projects for the development of NM services. Eight more institutes will start operating and at least two more cyclotrons and two PET-CTs will be installed in these NM establishments. To serve the huge populations of this country, private organizations are also coming up and it is expected that 
the coming decade will flourish more NM facilities, especially by installing state of the art PET-CT systems and PET-MRIs either in government as well as private sectors.

Now comes the big question of developing trained manpower in NM field. As it's a multidisciplinary branch of Medicine, it requires not only specific medical competences but also supports from radio-pharmacists, radio-chemists and medical physicists. So, this is a high demand of time that we should pay attentions to.

The development of human resources for NM should involve partnership with the government, professional bodies (e.g. SNMB) and academic bodies (e.g. BSMMU) (6). However, challenges of human resources in Bangladesh are similar to other developing countries that we cannot ignore (7).

At present, NINMAS is the only institute in the country which offers a five years post graduate course for the NM physicians under Bangabandhu Sheikh Mujib Medical University (BSMMU). This course may be extended to other NM institutes. A formal course for the technologists is overdue. The Institute of Nuclear Medical Physics (INMP) at Atomic Energy Research Establishment (AERE), Savar, Dhaka is showing a new hope for development of manpower in medical physics. We should also keep exploring the possibility of training of our manpower abroad in conjunction with IAEA and other international and regional bodies.

The landscape of medical science is continually changing and evolving. In next decade, most promising area of NM will be Theranostics, the term used for diagnostic imaging and targeted therapy at the molecular and cellular level with a single agent (8). Though the history of radionuclide therapy is quite long for thyroid carcinoma and hyperthyroidism, exploring other agents to use routinely for treating benign and malignant diseases with minimal side effects appear to be vital now. The key to successful practice of theranostics is to ensure an appropriate infrastructure that includes trivial factors like space, required equipments, radiopharmaceuticals and trained personnel who will ascertain the logistics and ensure treatment process to flow in a continuous manner (9).
The government of Bangladesh has set a goal of digital transformation back in 2009 and significant development occurred in expansion of the information technology sector. In 2019, the number of mobile phones and internet users in the country stands at 161.8 million and 96.2 million respectively. The NM service of the country is also taking advantages of the 'Digital Bangladesh' and in the next decade we hope for complete digitalization of our services (2).

2021 will be a milestone for Bangladesh. Not only we celebrate the $50^{\text {th }}$ jubilee of our independence but also, we will enter into a new decade. Making NM services more accessible and efficient will lead to prompt diagnosis and treatment and contribute significantly in sustainable development goals (SDG) of health sector. We should prepare ourselves to take the challenges of the new decade and hope for the best.

\section{REFERENCES}

1. The World Bank in Bangladesh: Overview. www.worldbank.org/en/country/bangladesh/overview

2. Socio-economic progress and recent macroeconomic development in Bangladesh (2019) www.mof.portal.gov.bd

3. Hasan M. Present, past and future of nuclear medicine in Bangladesh. Bangladesh Journal of Nuclear Medicine. 2014;17(1):08-9.

4. Hussain R. History and Perspectives of Nuclear Medicine in Bangladesh. Asia Oceania Nucl Med Biol, 2016;4(1) 55-58 doi:107508/aojnmb.2016.04.009

5. How Bangladesh is Breaking Down Barriers to Nuclear Medicine. (2016),

https://www.iaea.org/newscenter/news/how-bangladesh-is-bre aking-down-barriers-to-nuclear-medicine

6. Gopinathan N. Human resource development in nuclear medicine in developing countries. Indian Journal of Nuclear Medicine. 1998;13(3):115-9.

7. Begum SMF, Nisa L, Sarker AK. Theranostics in Bangladesh: Current Status, Challenges and Future Perspective. Nucl. Med Mol Imaging, 2019, 53:102-107 doi-org/101007/S13139-019-00590-1

8. Nisa L, Begum SMF. The age of Theranostics in Nuclear Medicine: Bangladesh Standpoint. Bangladesh J. Nucl. Med, 2018; 21(2) 115-117 doi-org/10.3329/bjnmv21i2.40362

9. Bodei L, Chiti A, Modlin IM, Scott AM, Schöder H. The path to the future: Education of nuclear medicine therapeutic specialists as responsible physicians. Journal of Nuclear Medicine. 2019 Dec 1;60(12):1663-4. 